\title{
Exam Handbook
}

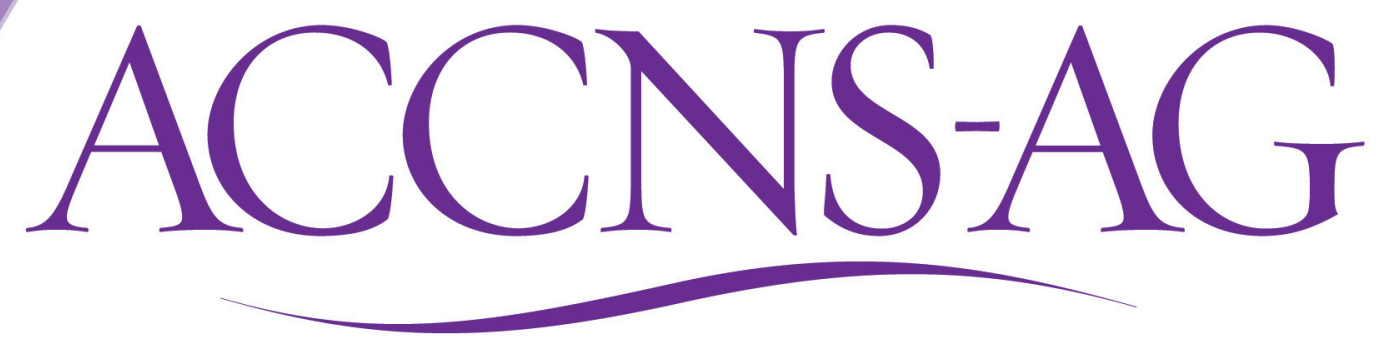

Adult-Gerontology

Clinical Nurse Specialist Certification (Wellness Through Acute Care)

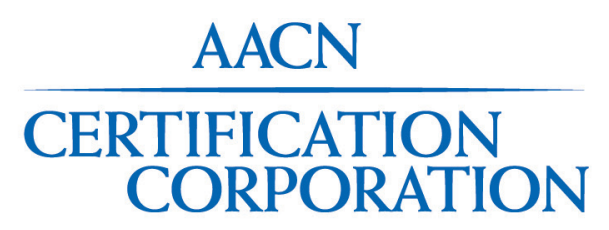




\section{MISSION}

AACN Certification Corporation drives patient health and safety through comprehensive credentialing of acute and critical care nurses, advancing practice consistent with standards of excellence.

\section{VISION}

All nurses caring for acutely and critically ill patients and their families are certified.

\section{VALUES}

As the Corporation advances its mission and vision to fulfill its purpose and inherent obligation of driving the health and safety of patients experiencing acute and critical illness, we are guided by a set of deeply rooted values. These values are the foundation upon which we build our relentless pursuit of excellence.

- Integrity - We demonstrate sound judgment, ethical behavior and accountability in all we do.

- Inclusion - We build an equitable culture, inviting the full contribution of all people.

- Transformation - We drive change and innovation to positively impact the healthcare system and improve the lives of patients, families and nurses.

- Leadership - We advocate and influence to achieve optimal outcomes and healthy work environments.

- Relationships - We collaborate and advance partnerships, honoring each individual to strengthen the collective.

\section{ETHICS}

AACN and AACN Certification Corporation consider the American Nurses Association (ANA) Code of Ethics for Nurses foundational for nursing practice, providing a framework for making ethical decisions and fulfilling responsibilities to the public, colleagues and the profession. AACN Certification Corporation's mission of public protection supports a standard of excellence where certified nurses have a responsibility to read about, understand and act in a manner congruent with the ANA Code of Ethics for Nurses.

The following AACN Certification Corporation programs have been accredited by the Accreditation Board for Specialty Nursing Certification (ABSNC).

\begin{tabular}{|c|c|c|c|}
\hline $\mathrm{ABSN} \mathrm{C}^{\mathrm{A}} \begin{array}{l}\text { Accredited } \\
\text { Program }\end{array}$ & $\begin{array}{l}\text { CCRN }^{\circ} \text { (Adult) } \\
\text { CMC }^{\circ}\end{array}$ & $\mathrm{CCRN}^{\circ}$ (Pediatric) & $\mathrm{CCRN}^{\circ}$ (Neonatal) \\
\hline
\end{tabular}

The following AACN Certification Corporation programs have been accredited by the National Commission for Certifying Agencies (NCCA).

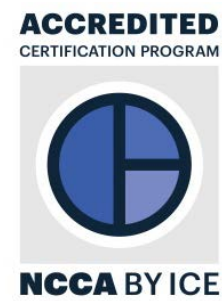

$\mathrm{PCCN}^{\odot} \quad \mathrm{ACNPC}^{\circ} \mathrm{AG}^{\oplus}$

ACCNS-AG ${ }^{\circ} \quad$ ACCNS- ${ }^{\circ} \quad$ ACCNS-N ${ }^{\circ}$

Our advanced practice certification programs, ACCNS-AG, ACCNS-P, ACCNS-N and ACNPC-AG, meet the National Council of State Boards of Nursing (NCSBN) criteria for APRN certification programs. 


\section{$\mathrm{AACN}$ \\ CERTIFICATION \\ CORPORATION}

Certification Organization for the American Association of Critical-Care Nurses

\section{ACCNS-AG EXAM HANDBOOK}

\section{Adult-Gerontology Clinical Nurse Specialist (wellness through acute care)}

As healthcare becomes increasingly complex and challenging, certification has emerged as a mark of excellence showing patients, employers and the public that a nurse possesses a defined body of knowledge and has met the rigorous requirements to achieve specialty and/or subspecialty certification.

AACN Certification Corporation programs were created to protect healthcare consumers by validating the knowledge of nurses who care for and/or influence the care delivered to the acutely and critically ill. We are pleased to provide you with this handbook with information about our programs and how to apply for and take the ACCNS-AG certification exam.

Today, more than 132,000 practicing nurses hold one or more of these certifications from AACN Certification Corporation:

\section{Specialty Certifications}

CCRN $^{\circledR}$ is for nurses providing direct care to acutely/critically ill adult, pediatric or neonatal patients.

CCRN-K $\mathrm{K}^{\mathrm{TM}}$ is for nurses who influence the care delivered to acutely/critically ill adult, pediatric or neonatal patients, but do not primarily or exclusively provide direct care.

CCRN-E ${ }^{\mathrm{TM}}$ is for nurses working in a teleICU monitoring/caring for acutely/critically ill adult patients from a remote location.

PCCN $^{\circledR}$ is for progressive care nurses providing direct care to acutely ill adult patients.

$\mathrm{PCCN}-\mathrm{K}^{\mathrm{TM}}$ is for nurses who influence the care delivered to acutely ill adult patients, but do not primarily or exclusively provide direct care.

\section{Subspecialty Certifications}

$\mathrm{CMC}^{\circledR}$ is for certified nurses providing direct care to acutely/critically ill adult cardiac patients.

$\mathrm{CSC}^{\circledR}$ is for certified nurses providing direct care to acutely/critically ill adult patients during the first 48 hours after cardiac surgery.

\section{Advanced Practice Consensus Model-Based Certifications}

ACNPC-AG ${ }^{\circledR}$ is for nurses educated at the graduate level as adult-gerontology acute care nurse practitioners.

The ACCNS credentials are for nurses educated at the graduate level as clinical nurse specialists to provide care across the continuum from wellness through acute care:

ACCNS-AG ${ }^{\circledast}$ is for the adult-gerontology clinical nurse specialists educated to care for adult-gerontology patients.

ACCNS- $\mathrm{P}^{\circledR}$ is for the pediatric clinical nurse specialists educated to care for pediatric patients.

ACCNS-N ${ }^{\circledR}$ is for the neonatal clinical nurse specialists educated to care for neonatal patients.

\section{Advanced Practice Certifications}

With implementation of the Consensus Model in 2015, ACNPC and CCNS are available as renewal options only:

ACNPC $^{\circledR}$ is for acute care nurse practitioners educated to provide care to adult patients.

CCNS $^{\circledR}$ is for acute/critical care clinical care specialists educated to provide care to adult, pediatric or neonatal patients.

AACN Certification Corporation's APRN certifications are recognized for licensure in all U.S. states and territories.

We continually seek to provide quality certification programs that meet the changing needs of nurses and patients. Please visit www.aacn.org/certification, or call 800-899-2226 for more information about the above certifications.

Thank you for your commitment to patients and their families and to becoming certified. 


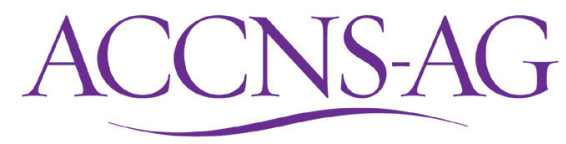

Please direct inquiries to:

AACN Certification Corporation, 27071 Aliso Creek Road, Aliso Viejo, CA 92656

800-899-2226 • Fax: 949-362-2020 • APRNcert@aacn.org

Please include your AACN customer number with all correspondence to AACN Certification Corporation. 


\section{Contents}

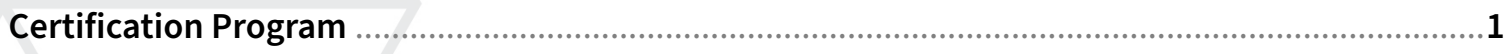

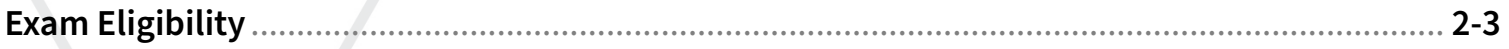

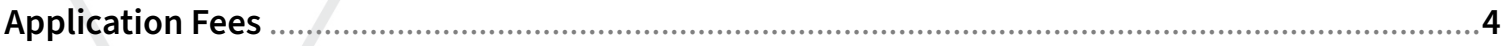

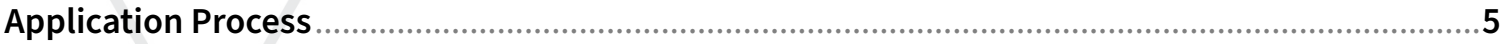

Certification Renewal

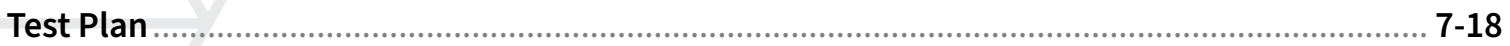

- Overview

- Patient Care Problems

- Skills and Procedures

- Validated Competencies

Sample Questions

Exam Bibliography

AACN Products for ACCNS-AG Exam Preparation

\section{Forms}

Educational Eligibility Form (EEF)

ACCNS-AG Exam Application (1st and 2nd pages of 3-page application)

The following information can be found in the Certification Exam Policy Handbook online at www.aacn.org/certhandbooks:

- AACN Certification Programs

- Name and Address Changes

- Confidentiality of Exam Application Status

- Testing Options

- Exam Scheduling and Cancellation

- Exam Day Experience
- Duplicate Score Reports

- Recognition of Certification

- Use of Credentials

- Denial of Certification

- Revocation of Certification

- Review and Appeal of Certification Eligibility 


\section{ACCNS-AG Certification Program}

ACCNS-AG ${ }^{\circledR}$ is an entry-level advanced practice certification for clinical nurse specialists (CNSs) educated at the graduate level to provide advanced nursing care across the continuum of healthcare services - wellness through acute care - to meet the specialized needs of the adult-gerontology patient population (young adults, older adults and frail elderly).

\section{ACCNS-AG ${ }^{\circledR}$ Registered Service Mark}

ACCNS-AG is a registered service mark and denotes certification as an adult-gerontology clinical nurse specialist as granted by AACN Certification Corporation.

Clinical nurse specialists who have not achieved ACCNS-AG certification or whose ACCNS-AG certification has lapsed are not authorized to use the ACCNS-AG credential.

Misuse of the credential is viewed by AACN Certification Corporation as misleading to the public and may result in denial or revocation of certification.

\section{Purpose and Rationale}

The purpose of ACCNS-AG certification is to help ensure public protection. New graduate clinical nurse specialists are required to pass a psychometrically sound exam that measures the advanced practice competencies needed to perform safely and effectively as a newly licensed, entrylevel clinical nurse specialist with authority to diagnose and prescribe.

The ACCNS-AG exam is based on a study of practice, also known as a job analysis. The study of practice, conducted at least every five years, validates the knowledge, skills and abilities required for safe and effective advanced practice as an entry-level adult-gerontology CNS.

The test plan, which provides an outline of exam content, is developed by an expert ACCNS-AG panel based on the results of the study of practice.

Eligibility requirements for ACCNS-AG certification are based on the Consensus Model for APRN Regulation and the National Council of State Boards of Nursing (NCSBN) Criteria for APRN Certification Programs (2012).

An unencumbered U.S. license as RN or APRN is required to validate that a nurse is following accepted legal nursing practice in compliance with State Board of Nursing requirements.

State Boards of Nursing may use ACCNS-AG exam results as a factor in making APRN licensure determinations. As regulatory partners, AACN Certification Corporation's master's-prepared registered nurses are required to evaluate graduate program curricula for compliance with national and state standards.

\section{Exam Structure and Content}

The ACCNS-AG exam is three-and-a-half ( $31 / 2)$ hours and consists of 175 multiple-choice items. Of the 175 items, 150 are scored. The remaining 25 items are used to gather statistical data on item performance for future exams.

Sixty-five percent (65\%) of the items test clinical judgment related to nursing care of the adult-gerontology patient population (wellness through acute care).

The remaining items (35\%) test non-clinical judgment knowledge required for adult-gerontology CNS practice and may refer to adult, pediatric or neonatal patient situations.

\section{Passing Point/Cut Score}

A criterion-referenced standard setting process, known as the modified Angoff, is used to establish the passing point/cut score for the exam. Each candidate's performance on the exam is measured against a predetermined standard.

The passing point/cut score for the exam is established using a panel of subject matter experts, an exam development committee (EDC), who carefully reviews each exam question to determine the basic level of knowledge or skill that is expected. The passing point/cut score is based on the panel's established difficulty ratings for each exam question.

Under the guidance of a psychometrician, the panel develops and recommends the passing point/cut score, which is reviewed and approved by AACN Certification Corporation. The passing point/cut score for the exam is established to identify individuals with an acceptable level of knowledge and skill. All individuals who pass the exam, regardless of their score, have demonstrated an acceptable level of knowledge.

\section{Score Reporting}

For purposes of evaluating educational programs, exam pass/fail status and a breakdown of exam scores by content area will be reported to the candidate's program director.

The Board of Nursing in the state(s) in which you have applied for or intend to apply for licensure will also be notified of your pass/fail status. 


\section{ACCNS-AG Exam Eligibility}

\section{Licensure}

Current, unencumbered U.S. ${ }^{1} \mathrm{RN}$ or APRN licensure is required.

- An unencumbered license is not currently being subjected to formal discipline by the board of nursing in the state(s) in which you are practicing and has no provisions or conditions that limit your nursing practice. ${ }^{2}$

- Provisions or conditions may include, but are not limited to, direct supervision of practice, drug administration limitations and/or practice area exclusions.

- Documentation of all provisions and conditions from the board or its designee must be reviewed prior to approval for testing.

- Candidates and ACCNS-AG-certified nurses must notify AACN Certification Corporation within $\mathbf{3 0}$ days if any provisions or conditions are placed on their RN or APRN license(s).

Nurses who hold an encumbered license, meaning a provision or condition that limits their nursing practice has been placed against their RN and/or APRN license, may be eligible for Conditional Certification. Email APRNcert@aacn.org to inquire.

- Conditional Certification is a temporary status granted to a nurse seeking APRN certification who has a provision or condition placed against their RN and/or APRN license.

- Conditional status will be changed to Active status once the provision or condition against the $\mathrm{RN}$ and/ or APRN license has been removed and the license is unencumbered.

- If the SBON suspends or revokes the nurse's license and he/she cannot practice, certification will be revoked.

\section{Education}

Completion of a graduate-level advanced practice education program that meets the following requirements:

1. The program is through a college or university that offers a CCNE or ACEN accredited master's or higher degree in nursing with a concentration as an adult- gerontology clinical nurse specialist (CNS) covering the spectrum of wellness through acute care.

2. Both direct and indirect clinical supervision must be congruent with current $A A C N$ and nursing accreditation guidelines.

3. The curriculum includes but is not limited to:

a. Biological, behavioral, medical and nursing sciences relevant to practice as an adultgerontology CNS, including advanced pathophysiology, pharmacology and physical assessment

b. Legal, ethical and professional responsibilities of the CNS

c. Supervised clinical practice relevant to the specialty

4. The curriculum meets the following criteria:

a. The curriculum is consistent with the competencies of adult-gerontology CNS practice.

b. The instructional track/major has a minimum of 500 supervised clinical practice hours overall.

c. All clinical hours are focused on the direct care of adult-gerontology patients and completed within the U.S.

d. The supervised clinical experience is directly related to the knowledge and all role components of the adult-gerontology CNS.

Completion of 500 supervised clinical practice hours in all roles of the adult-gerontology CNS within the graduate-level educational program is required. A portion of the total clinical hours must be focused on wellness and a portion on acute care, in the adult-gerontology patient population (includes young adults, older adults and frail elderly).

Didactic coursework with content related to the care of adult-gerontology patients, covering wellness through acute care, is required. Content must be in alignment with the ACCNS-AG Test Plan.

- The director of your education program must complete an Educational Eligibility Form (see page 26).

continued

\footnotetext{
${ }^{1}$ Includes District of Columbia and U.S. territories of Guam, Virgin Islands, American Samoa and Northern Mariana Islands

${ }^{2}$ If a restriction (temporary or permanent) is placed on an RN or APRN license for an incident that occurred prior to obtaining the license, AACN Certification Corporation will evaluate such an occurrence on a case-by-case basis to determine if exam eligibility requirements are met.
} 


\section{ACCNS-AG Exam Eligibility (continued)}

- Official, final transcripts for all graduate-level nursing coursework showing degree/date conferred are required.

- Secure, electronic transcripts may be emailed directly from the school to APRNcert@aacn.org.

- Mailed transcripts must be sent to AACN in a sealed envelope directly from the school.

- If you are making up clinical or didactic coursework to meet ACCNS-AG exam eligibility, courses must be completed in a post-graduate certificate or DNP program.
AACN Certification Corporation may adopt additional eligibility requirements at its sole discretion. Any such requirements will be designed to establish, for the purposes of ACCNS-AG certification, the adequacy of a candidate's knowledge in care of the acutely and/or critically ill.

The ACCNS-AG exam aligns with requirements of the Consensus Model for APRN Regulation and meets the National Council of State Boards of Nursing (NCSBN) Criteria for APRN Certification Programs. ACCNS-AG certification is accepted in all states that recognize the CNS as an APRN role.

Questions regarding eligibility should be emailed to APRNcert@aacn.org. 


\section{Application Fees}

\begin{tabular}{|c|c|c|}
\hline ACCNS-AG Fees & Member & Nonmember \\
\hline Computer-Based Exam & $\$ 265$ & $\$ 375$ \\
\hline Retest & $\$ 205$ & $\$ 310$ \\
\hline Renewal by Exam & $\$ 205$ & $\$ 310$ \\
\hline
\end{tabular}

Payable in U.S. funds. Fees are subject to change without notice. A $\$ 15$ fee will be charged for a returned check. Applicants determined to be ineligible for the ACCNS-AG exam will have their application fee refunded. 


\section{Online Application Process}

- Register online for computer-based testing at www.aacn.org/certification > Get Certified

- Before you get started, have available the following:

- RN or APRN license number and expiration date

- Credit card (Visa, MasterCard, Discover or American Express)

- Official, final transcript(s) for all graduate-level nursing coursework are required

- Must show degree and date conferred

- Secure, electronic transcript may be emailed directly from the school to APRNcert@aacn.org

- Mailed transcripts must be sent to AACN in a sealed envelope directly from the school

- Educational Eligibility Form completed by program director

- Paper form or online via Program Director Portal

\section{Paper Application Process}

Complete and submit the following in one envelope:

- Official, final transcript(s) for all graduate-level nursing coursework are required

- Must show degree and date conferred

- Secure, electronic transcript may be emailed directly from the school to APRNcert@aacn.org

- Mailed transcripts must be sent to AACN in a sealed envelope directly from the school

- Educational Eligibility Form on page 26

- To be completed/signed by director of CNS program; originals only, or emailed direct from school

- Application/Honor Statement on pages 27-29

- Fill in all requested information, sign and date

- Application fee

- Credit card, check or money order

Use your legal name on the application.

This name must match photo identification used for exam entry and will be the name printed on your certificate.

\section{Receive email notification of receipt of application}

- AACN will send you an email confirming that your application has been received and forwarded to a Certification specialist for evaluation.

- Evaluation will take 1 to 4 weeks - depending on whether we need to contact your school to request additional information to confirm your eligibility.

\section{Receive confirmation email}

- Once all required documentation is received and your application is approved, AACN will send an email with a link to schedule your exam. The email will include the eligibility period during which you must take the exam - normally a 90-day window, but currently a 180-day window.

- In your AACN customer dashboard, you will also find a "Schedule Exam" link.

- If you do not receive your confirmation email after applying for an exam, please email APRNcert@aacn.org.

\section{Schedule the exam}

- In your confirmation email from AACN, you will find a link to schedule your exam appointment - or from your AACN customer dashboard, you can click "Schedule Exam." Both links will take you to the AACN Scheduling page.

- Before you select an exam date, you will need to choose your preferred computer-based testing options - at a PSI Testing Center or via Live Remote Proctoring from your computer in a quiet, private location. For details refer to the Certification Exam Policy Handbook at www.aacn.org/certhandbooks.

- If you are taking a paper-and-pencil exam or testing outside the U.S., AACN and PSI will coordinate with you to schedule you exam appointment.

\section{Sit for the exam}

- Upon completion of computer-based exams, results will show on-screen, and a detailed score report will be emailed to you within 24 hours.

- Results of paper-and-pencil exams are received by mail 6 to 8 weeks following testing.

- Successful candidates will receive their wall certificate approximately 3 to 4 weeks after exam results are received. 


\section{ACCNS-AG Certification Renewal}

\section{Purpose and Limitations of Renewal Options}

The purpose of certification renewal is to promote continued competence. The renewal process helps to maintain an up-to-date knowledge base through one of the following options:

- Practice hours and CE Points including pharmacology CE

- Practice hours, pharmacology CE and passing the certification exam

- CE Points including pharmacology CE and passing the certification exam

Following are the limitations to the components of the renewal options:

- CE limitations include content quality and relevance to practice as well as an individual's ability to selfselect CEs most pertinent to the individual's practice and educational needs.

- Limitations of practice hours include the quality of the practice environment and limitations on learning opportunities.

- One limitation of the exam is not assessing new competencies, as exam competencies were validated through initial certification.

Requiring multiple components for renewal rather than one decreases the limitations and furthers the goal of continued competence.

\section{Renewal Period}

ACCNS-AG certification is granted for a period of 5 years.

Your certification period begins the first day of the month in which the ACCNS-AG exam is passed and ends 5 years later, e.g., February 1, 2022 through January 31, 2027.

Renewal notifications will be emailed to you starting 4 months prior to your scheduled ACCNS-AG renewal date. You are responsible for renewing your certification even if you do not receive a renewal notification. Refer to www.aacn.org/certification > Renew Certification for current information.

\section{Eligibility}

To maintain a current ACCNS-AG certification, renewal must be completed prior to your certification expiration date.

To reobtain certification you would need to meet the current ACCNS-AG initial exam eligibility requirements (based on educational preparation) and pass the ACCNS-AG exam.

Eligible candidates for ACCNS-AG renewal must hold current, unencumbered U.S. ${ }^{1}$ RN or APRN license. An unencumbered license has not been subjected to formal discipline by the board of nursing in the state(s) in which you practiced and had no provisions or conditions that limited your nursing practice during the 5-year certification period.

ACCNS-AG-certified nurses must notify AACN Certification Corporation within $\mathbf{3 0}$ days if any provisions or conditions are placed on their RN or APRN license(s).

An APRN whose license is encumbered may be eligible for Conditional Certification; see page 2.

\section{Renewal Options}

At renewal time you may seek certification renewal by one of 3 options:

Option 1 - 1,000 Practice Hours and 150 CE Points

Option 2 - 1,000 Practice hours, 25 Pharmacology CE and Exam

\section{Option 3 - 150 CE Points and Exam}

For complete information refer to the ACCNS-AG Renewal Handbook online at www.aacn.org/certhandbooks.

\footnotetext{
${ }^{1}$ Includes District of Columbia and U.S. territories of Guam, Virgin Islands, American Samoa and Northern Mariana Islands
} 


\section{PAGE 1 OF 12 \\ Overview}

The ACCNS-AG certification program is based on competencies from nationally recognized organizations such as the National Association of Clinical Nurse Specialists and the American Association of Colleges of Nursing, as well as a study of practice, also known as a job analysis, that is conducted at least every five years. This study of practice validates the knowledge, skills and abilities required for safe and effective advanced practice as an adult-gerontology CNS. The test plan is constructed using entry-level competencies. All competencies are listed on pages 7-12 of the test plan.

The test plan, which provides an outline of exam content, is developed by an expert CNS panel based on the results of the study of practice. The organizing framework for all AACN Certification Corporation exams is the AACN Synergy Model for Patient Care ${ }^{\mathrm{TM}}$. Please refer to pages 24 and 25 for more about the Synergy Model.

Following are the major content dimensions of the adult-gerontology CNS, wellness through acute care, (ACCNS-AG) exam, which are part of the test plan:

- Patient Care Problems validated by the study of practice as those regularly encountered by the entry-level CNS. Refer to pages 2-4 for the list of patient care problems.

- Skills and Procedures validated by the study of practice as those pertinent to the entry-level CNS. In addition to classifying exam items according to the specified patient care problems and related validated competencies, items may require an understanding of skills and procedures pertinent to adult-gerontology CNS practice.

Refer to pages 5-6 for the list of skills and procedures.

- Validated Competencies include Clinical Judgment, Advocacy/Moral Agency, Caring Practices, Response to Diversity, Facilitation of Learning, Collaboration, Systems Thinking and Clinical Inquiry.

Refer to pages 7-12 for a complete listing of the ACCNS-AG Validated Competencies.

\section{Integrated Concepts}

To meet criteria for regulatory sufficiency, APRN certification exams must test national practice standards and core competencies for the role and patient population(s) being certified. The ACCNS-AG exam incorporates the following standards and competencies:

- National CNS Competency Task Force. Clinical Nurse Specialist Core Competencies. 2010.

- American Association of Colleges of Nursing. Adult-Gerontology Clinical Nurse Specialist Population Focused Competencies. Washington, DC: AACN Colleges; 2010.

- Advanced Practice Work Group. Bell L, ed. Scope and Standards for Acute and Critical Care Clinical Nurse Specialist Practice. Aliso Viejo, CA: American Association of Critical-Care Nurses; 2014. 


\section{CLINICAL JUDGMENT (65\%)}

Validated Competencies are detailed on pages 7-12 of this test plan.

\section{A. Cardiovascular (13\%)}

1. Acute coronary syndromes

2. Acute inflammatory disease (e.g., myocarditis, endocarditis, pericarditis)

3. Cardiac surgery
a. On-pump
b. Off-pump
c. Valve procedures
d. Hybrid procedures
e. Revascularization procedures

4. Cardiac tamponade

5. Cardiac trauma (blunt and penetrative)

6. Cardiogenic shock

7. Cardiomyopathies (e.g., hypertrophic, dilated, restrictive, idiopathic)

8. Coronary artery disease

9. Dyslipidemia

10. Dysrhythmias

11. Heart failure
a. Acute
b. Chronic
C. Advanced

12. Hypertension

13. Hypertensive urgencies or emergencies

14. Peripheral vascular insufficiency (e.g., acute arterial occlusion, carotid artery stenosis, endarterectomy, peripheral stents and Fem-Pop bypass)

15. Pulmonary edema

16. Ruptured or dissecting aneurysm

\section{B. Pulmonary (11\%)}

1. Acute pulmonary embolus

2. Acute respiratory distress syndrome (ARDS)

3. Acute respiratory failure
4. Air-leak syndromes (e.g., pneumothorax, pulmonary interstitial emphysema, pneumopericardium, pneumomediastinum)

5. Airway obstruction (e.g., angioedema, mucus plug, air space occupying lesions)

6. Aspiration

7. Asthma/reactive airway disease

8. Chronic lung disease (e.g., COPD, exacerbation, interstitial pulmonary fibrosis, cystic fibrosis)

9. Chronic respiratory failure (e.g., ventilator dependency)

10. Obstructive sleep apnea

11. Pulmonary arterial hypertension

12. Pulmonary infections (e.g., pneumonia, tuberculosis)

13. Thoracic surgery (e.g., lung reduction, pneumonectomy, lobectomy, tracheal, lung transplant)

14. Thoracic and pulmonary trauma and injuries (e.g., lung contusions, fractured ribs, hemothorax)

15. Restrictive lung disease (e.g., obesity hypoventilation, tumor metastasis, pulmonary fibrosis)

16. Pleural effusion

C. Endocrine (4\%)

1. Diabetes mellitus

2. Diabetic ketoacidosis (DKA) and hyperglycemic hyperosmolar state (HHS)

3. Hyperglycemia

4. Hypoglycemia

D. Hematology/Immunology/Oncology (3\%)

1. Anemias (e.g., microcytic, macrocytic)

2. Coagulopathies (e.g., VTE, DIC, hypercoagulable states)

3. Myelosuppression (e.g., neutropenia, anemia, thrombocytopenia)pain 
E. Gastrointestinal (5\%)

1. Abdominal trauma

2. GI hemorrhage

3. Bowel infarction/obstruction/perforation

4. Gastroesophageal reflux

5. Gl infectious disorders

6. GI motility disorders (e.g., constipation, diarrhea, ileus, gastroparesis)

7. Gl surgeries

8. Hepatorenal syndrome

9. Liver disease (e.g., hepatitis, hepatic failure)

10. Malnutrition

11. Nausea, vomiting

12. Pancreatitis

F. Renal/Genitourinary (4\%)

1. Acute kidney injury (AKI)

2. Chronic kidney disease (CKD)

3. Contrast-induced nephropathy

4. Electrolyte imbalances

5. Fluid volume imbalances

6. Incontinence

7. Infections (e.g., UTI, PID, STDs)

\section{G. Integumentary (1\%)}

1. Pressure ulcers (pressure injuries)

2. Wounds (surgical and non-surgical)

\section{H. Musculoskeletal (3\%)}

1. Mobility disorders (e.g., immobility, debility secondary to acute, chronic or critical illness)

2. Infections (e.g., necrotizing fasciitis, osteomyelitis)

3. Neuromuscular dysfunction related to illness

4. Traumatic fractures

I. Neurology (5\%)

1. Brain death

2. Encephalopathy

3. Head and brain trauma/injury
4. Intracranial hypertension

5. Intracerebral hemorrhage

6. Seizure disorders

7. Spinal cord injury

8. Stroke

9. Vascular malformation

J. Psychosocial/Behavioral/Cognitive Health (4\%)

1. Aggression

2. Agitation

3. Anxiety disorders (e.g., PTSD, OCD, fears, phobias)

4. Capacity for decision making

5. Delirium

6. Dementia

7. Medical nonadherence

8. Mood disorders (e.g., depression)

9. Post-ICU syndrome

10. Risk-taking behaviors (e.g., tobacco, unprotected sex)

11. Substance abuse

12. Suicidal behavior

K. Factors Influencing Health Status (4\%) (risk assessment, prevention and wellness)

1. Advance care planning

2. Cancer prevention (e.g., tobacco cessation, sunscreen)

3. Caregiver burden

4. Health literacy

5. Immunizations

6. Mental health screenings (e.g., depression, suicidal ideation, eating disorders)

7. Nutrition and weight management

8. Pain prevention and management

9. Prudent heart living

10. Risk-taking behaviors (e.g., substance use)

11. Secondary prevention (e.g., cardiac rehab, pulmonary rehab)

12. Sleep hygiene 
L. Multisystem (9\%)

1. Acid-base imbalances

2. Bariatric care issues

3. Compartment syndrome

4. Distributive shock (e.g., anaphylaxis, neurogenic)

5. End-of-life issues

6. Failure to thrive

7. Hospital-acquired conditions (e.g., CAUTI, CLABSI, falls, pressure ulcers/pressure injuries)

8. Hypovolemic shock

9. Hypoxic ischemic encephalopathy

10. Infectious diseases (e.g., congenital, viral, bacterial, hospital-acquired infections)

11. Multisystem trauma

12. Pain

13. Palliative care issues

14. Rhabdomyolysis

15. Sensory impairment (e.g., hearing loss)

16. Sepsis/septic shock and MODS

17. Toxic exposures, ingestions and inhalations (e.g., overdose, carbon monoxide, lead, asbestos)

18. Withdrawal (e.g., alcohol, opioids, benzodiazepines)
II. PROFESSIONAL CARING AND ETHICAL PRACTICE (35\%)

Validated Competencies are detailed on pages 7-12 of this test plan.
A. Advocacy/Moral Agency (4\%)
B. Caring Practices (6\%)
C. Response to Diversity (3\%)
D. Facilitation of Learning ( $5 \%)$
E. Collaboration (5\%)
F. Systems Thinking (6\%)
G. Clinical Inquiry (6\%)

The sum of these percentages is not 100 due to rounding. Order of content does not necessarily reflect importance. 


\section{PAGE 5 OF 12 \\ Skills and Procedures}

In addition to classifying exam items according to the specified patient care problems and identifying related competencies on the following pages, items may require an understanding of skills and procedures pertinent to the adult-gerontology CNS. The study of practice sought to determine whether selected skills and procedures are performed and important to the adult-gerontology CNS. If applicable to assessment of knowledge of the patient care problem, the following skills and procedures may be incorporated within items. This list is not intended to be all inclusive. Common nursing skills and procedures also may be included in the exam content.

\section{Cardiovascular}

- Adjust implantable cardioverter defibrillators (ICD)

- Determine lead selection for patient care monitoring (e.g., ST segment monitoring)

- Direct cardiopulmonary resuscitation

- Interpret 12-lead ECGs

- Interpret hemodynamic values

- Interpret noninvasive hemodynamic values

- Manage patient with arterial sheath removal

- Manage patient with dysrhythmias

- Manage patient with hemodynamics with pharmacologic intervention

- Manage patient with life vest

- Manage patient with temporary transvenous pacemakers

- Manage patient with transcutaneous (external) pacemakers

- Manage patient with venous sheath removal

- Perform synchronized cardioversion

- Use data from echocardiograms

\section{Pulmonary}

- Initiate mechanical ventilation

- Manage patient with artificial airways

- Manage patient with chest tubes

- Manage patient with mechanical ventilation

- Manage patient with multi-modal oxygen therapy

- Manage patient with noninvasive ventilation/CPAP

- Perform end-tidal $\mathrm{CO}_{2}$ monitoring

- Perform extubation

- Perform terminal ventilator withdrawal

- Remove chest tube

\section{Endocrine}

- Manage patient with corticosteroid tapering

- Manage patient with fluid and electrolyte levels of endocrine disorders

- Manage patient with glycemic abnormalities

- Manage patient with insulin infusions

- Manage patient with insulin pumps

\section{Hematology/Immunology/Oncology}

- Manage patient with blood and blood products

- Manage patient with cancer treatment symptoms

- Manage patient with immunosuppression therapy

\section{Gastrointestinal}

- Manage patient with drainage catheters (e.g., biliary drains)

- Manage patient with enteral nutrition

- Manage patient with large-bore nasogastric tubes

- Manage patient with PEG/JT catheters

- Manage patient with small-bore nasogastric tubes

\section{Integumentary}

- Implement measures to prevent surgical site infections

- Implement pressure ulcer (pressure injury) prevention strategies

- Manage patient with pressure ulcers (pressure injuries)

- Provide wound care

- Stage pressure ulcers (pressure injuries) 


\section{Skills and Procedures}

\section{Neurology}

- Initiate organ procurement after brain death

- Manage patient with epidural catheters

- Manage patient receiving neuromuscular blockade

- Manage patient undergoing targeted temperature management

\section{Behavioral}

- Use de-escalation techniques (e.g., crisis prevention)

- Manage assaultive behavior

- Manage patient in restraints

- Suggest restraint alternatives

\section{Multisystem}

- Implement measures to prevent hospital acquired infections

- Interpret diagnostic imaging (e.g., radiographic, CT, MRI)

- Manage patient with complex pain problems

- Provide nonpharmacological interventions for pain 


\section{Validated Competencies}

In addition to classifying exam items according to the previous specifications, each item is written to reflect one of the following competencies validated through the study of practice. The following competencies are eligible for assessing knowledge of content.

\section{CLINICAL JUDGMENT}

\section{Core CNS Competencies}

- Conducts comprehensive, holistic, wellness and illness assessments using known or innovative evidence-based techniques and tools, and direct and indirect methods

- Obtains data about context and etiologies (including both non-disease and disease-related factors) necessary to formulate differential diagnoses and plans of care, and to identify and evaluate outcomes

- Assesses the effects of interactions among the individual, family, community and social systems on health and illness

- Synthesizes assessment data, advanced knowledge and experience using critical thinking and clinical judgment to formulate differential diagnoses for clinical problems amenable to CNS intervention

- Prioritizes differential diagnoses to reflect those conditions most relevant to signs, symptoms and patterns amenable to CNS interventions

- Selects interventions that may include, but are not limited to:

- Application of advanced nursing therapies

- Initiation of interdisciplinary team meetings

- Consultations and other communications to benefit patient care

- Management of patient medications

- Clinical procedures and other interventions

- Psychosocial support, including patient counseling and spiritual interventions

- Designs strategies, including advanced nursing therapies, to meet the multifaceted needs of complex patients and groups of patients

- Develops evidence-based clinical interventions and systems to achieve defined patient and system outcomes

- Prescribe pharmacologic interventions

- Prescribe non-pharmacologic interventions
- Prescribe diagnostic measures

- Prescribe equipment

- Prescribe treatments

- Provides direct care to selected patients based on the needs of the patient and the CNS's specialty knowledge and skills

- Assists staff in the development of innovative, costeffective programs or protocols of care

- Determines when evidence-based guidelines, policies, procedures and plans of care need to be tailored to the individual

- Assesses the impact of environmental/system factors on care

\section{Adult-Gerontology CNS Competencies}

- Conducts a comprehensive, holistic assessment of individuals, including those who are non-verbal, developmentally, functionally and/or cognitively impaired

- Assesses physiological and functional changes associated with aging and development across the adult continuum

- Assesses age-specific and genetic risk factors

- Assesses the interaction between acute and chronic physical and mental health problems

- Recognizes the presence of comorbidities and psychosocial issues that may impact optimal level of health

- Uses reliable and valid age-appropriate assessment instruments to assess acute and chronic health concerns, including but not limited to, mental status, delirium, dementia and pain

- Assesses for manifestations of health disorders or health disruptions (e.g., infection, adverse drug effect, dehydration, ischemia and geriatric syndromes)

- Evaluates for common mental health disorders such as depression, dementia, anxiety or substancerelated disorders 


\section{Validated Competencies}

- Conducts a pharmacologic assessment including: polypharmacy, drug interactions, over-the-counter and herbal product use, and the ability to safely and correctly store and self-administer medications

- Interprets values/results of laboratory and diagnostic tests with consideration of age, ethnicity and health status

- Assesses patient, family and caregiver's ability to implement complex plans of care

- Determines diagnoses in the complex patient and takes into consideration:

- Physiologic and pathophysiologic changes

- Morbidities and comorbidities

- Events across the life span

- Patient's pharmacologic history

- Manages or appropriately refers the patient with signs and symptoms of physical and mental health disorders across the adult lifespan, including geriatric syndromes

- Intervenes to prevent or minimize iatrogenesis

- Intervenes to facilitate transitions of care with emphasis on quality, safety and risk avoidance

- Designs a comprehensive, individualized, age- and disease-appropriate plan for health promotion

- Modifies health information, patient education programs and interventions for patients with sensory, perceptual, cognitive, and physical and mental illness limitations

\section{ADVOCACY/MORAL AGENCY}

\section{Core CNS Competencies}

- Facilitates resolution of ethical conflicts:

- Identifies ethical implications of complex care situations

- Considers the impact of scientific advances, cost, clinical effectiveness, patient and family values and preferences, and other external influences

- Applies ethical principles to resolving concerns across the three spheres of impact
- Promotes a practice climate conducive to providing ethical care

- Facilitates interdisciplinary teams to address ethical concerns, risks or considerations, benefits and outcomes of patient care

- Facilitates patient and family understanding of the risks, benefits and outcomes of proposed healthcare regimen to promote informed decision making

- Advocates for equitable patient care by:

- Participating in organizational, local, state, national or international level of policy-making activities for issues related to their expertise

- Evaluating the impact of legislative and regulatory policies as they apply to nursing practice and patient or population outcomes

- Promotes the role and scope of practice of the CNS to legislators, regulators, other healthcare providers and the public by communicating information that promotes nursing, the role of the CNS and outcomes of nursing and CNS practice through the use of the media, advanced technologies and community networks

- Advocates for the CNS/APRN role and for positive legislative response to issues affecting nursing practice

\section{Adult-Gerontology CNS Competencies}

- Facilitates decision-making regarding treatment options with the patient, family, caregivers and/or healthcare proxy

- Applies ethical principles in safeguarding the confidentiality, dignity and safety of all adult-older adult research participants, including the vulnerable and those with impaired decision-making capacity

- Balances patient and family preferences, threats to patient safety and risk/benefit analysis of interventions, such as fall prevention, pain management and treatment choices

- Articulates the role and significance of the CNS in improving healthcare outcomes for adults-older adults to other healthcare providers and the public 


\section{Validated Competencies}

\section{CARING PRACTICES}

\section{Core CNS Competencies}

- Evaluates nursing practice that considers safety, timeliness, effectiveness, efficiency, efficacy and patient-centered care

- Differentiates between outcomes that require care process modification at the individual patient level and those that require modification at the system level

- Leads development of evidence-based plans for meeting individual, family, community and population needs

- Determines nursing practice and system interventions that will promote patient, family and community safety

- Coaches patients and families to help them navigate the healthcare system

- Balances patient and family preferences, threats to patient safety and risk/benefit analysis of interventions, such as fall prevention, pain management and treatment choices

- Fosters professional accountability in self or others

\section{Adult-Gerontology CNS Competencies}

- Creates therapeutic, health-promoting, aging friendly environments

- Implements system-level changes based on analysis and evaluation of age-specific outcomes of care

- Intervenes to facilitate transitions of care with emphasis on quality, safety and risk avoidance

- Designs a comprehensive, individualized, age- and disease-appropriate plan for health promotion

- Develops age-specific, individualized treatment plans and interventions with consideration of cognitive status, sensory function, perception and the environment

- Advises patients, families and caregivers on how to address sensitive issues such as sexually transmitted diseases, suicide prevention, substance use and potential for abuse, driving and independent living, end-of-life concerns, advance care planning and finances

- Uses behavioral, communication and environmental-modification strategies with individuals who have cognitive and psychiatric impairments
- Coordinates care with other healthcare providers and community resources, with special attention to the needs of the non-verbal, developmentally and cognitively impaired patient and frail, older adult

\section{RESPONSE TO DIVERSITY}

Core CNS Competencies

- Develops age-specific clinical standards, policies and procedures

- Establishes collaborative relationships within and across departments that promote patient safety, culturally competent care and clinical excellence

- Designs health information and patient education appropriate to the patient's developmental level, health literacy level, learning needs, readiness to learn and cultural values and beliefs

\section{Adult-Gerontology CNS Competencies}

- Assesses patient, caregiver and family's preferences in relation to cultural, spiritual, quality of life and lifestyle choices

- Promotes healthcare policy and system changes that facilitate access to care and address biases (e.g., socioeconomic, ethnic, ageism, sexism, cultural and mental health stigma)

- Promotes system-wide policies and protocols that address cultural, ethnic, spiritual and intergenerational/age differences among patients, healthcare providers and caregivers

- Provides programs for the development of healthcare providers, students and caregivers that incorporate age-specific cultural competence and skills

\section{FACILITATION OF LEARNING}

\section{Core CNS Competencies}

- Facilitates the provision of clinically competent care by staff/team through education, role modeling, teambuilding and quality monitoring

- Provides education to individuals, families, groups and communities to promote knowledge, understanding and optimal functioning across the wellness-illness continuum 


\section{Validated Competencies}

- Participates in preprofessional, graduate and continuing education of nurses and other healthcare providers:

- Completes a needs assessment, as appropriate, to guide interventions with staff

- Promotes professional development of staff nurses and continuing education activities

- Implements staff development and continuing education activities

- Mentors nurses to translate research into practice

- Contributes to the advancement of the profession as a whole by disseminating outcomes of CNS practice through presentations and publications

- Mentors staff nurses, graduate students and others to acquire new knowledge and skills, and develop their careers

\section{Adult-Gerontology CNS Competencies}

- Coordinates formal and informal education for healthcare providers to improve adult-older adult healthcare outcomes

- Designs educational programs that enhance the knowledge of older adults, families and caregivers regarding normal changes of aging, myths and stereotypes of aging and health promotion, and prevention activities for older adults

- Provides education to patients, families, caregivers and the community, including but not limited to, the following topics:

- Health promotion

- High risk behaviors and their impact on health

- Interaction between physical and mental health

- Mentors healthcare providers, students and others to develop expertise in the care of the vulnerable adult including the frail elderly patient

\section{COLLABORATION}

\section{Core CNS Competencies}

- Uses advanced communication skills within therapeutic relationships to improve patient outcomes

- Provides leadership for collaborative, evidencebased revision of diagnoses and plans of care to improve patient outcomes
- Provides consultation to staff nurses, medical staff and interdisciplinary colleagues

- Initiates consultation to obtain resources, as necessary, to facilitate progress toward achieving identified outcomes

- Communicates consultation findings to appropriate parties consistent with professional and institutional standards

- Provides leadership in promoting interdisciplinary collaboration to implement outcome-focused patient care programs meeting the clinical needs of patients, families, populations and communities

- Uses leadership, team building, negotiation and conflict resolution skills to build partnerships within and across systems, including communities

- Assesses the quality and effectiveness of interdisciplinary, intra-agency and inter-agency communication and collaboration

- Provides leadership for establishing, improving and sustaining collaborative relationships to meet clinical needs

- Practices collegially with medical staff and other members of the healthcare team so that all providers' unique contributions to health outcomes will be enhanced

- Uses coaching and advanced communication skills to facilitate the development of effective clinical teams

- Provides leadership in conflict management and negotiation to address problems in the healthcare system

- Engages in a formal self-evaluation process, seeking feedback regarding own practice from patients, peers, professional colleagues and others

\section{Adult-Gerontology CNS Competencies}

- Provides consultation to the interdisciplinary team regarding the patient's mental status, home environment, mobility, functional status, self-care and caregiver's abilities

- Advocates for access to hospice and palliative care services for patients across the adult age spectrum

- Leads collaborative efforts of the healthcare team in focusing on individuals and systems issues that impact the adult-older adult patient 


\section{Validated Competencies}

- Balances patient and family preferences, threats to patient safety and risk/benefit analysis of interventions such as fall prevention, pain management and treatment choices

- Identifies potential risks to patient safety, autonomy and quality of care based on assessments across the patient, nurse and system spheres of impact

\section{SYSTEMS THINKING}

\section{Core CNS Competencies}

- Performs system-level assessments to identify variables that influence nursing practice and outcomes, including but not limited to, population variables, environment, system of healthcare delivery, regulatory requirements, internal and external political influences/stability, healthcare financing and recurring practices that enhance or compromise patient or system outcomes

- Provides leadership in maintaining a supportive and healthy work environment

- Coordinates the care of patients with use of system and community resources to ensure successful health/illness/wellness transitions, enhance delivery of care and achieve optimal patient outcomes

- Considers fiscal and budgetary implications in decision making regarding practice and system modifications:

- Evaluates use of products and services for appropriateness and cost/benefit in meeting care needs

- Conducts cost/benefit analysis of new clinical technologies

- Evaluates impact of introduction or withdrawal of products, services and technologies

- Leads system change to improve health outcomes through evidence-based practice:

- Specifies expected clinical and system-level outcomes

- Designs programs to improve clinical and system-level processes and outcomes

- Facilitates the adoption of practice change

- Evaluates impact of CNS and other nursing practice on systems of care using nurse-sensitive outcomes

- Disseminates outcomes of system-level change internally and externally
- Facilitates intra-agency and inter-agency communication

- Assesses system barriers and facilitators to adoption of evidence-based practices

\section{Adult-Gerontology CNS Competencies}

- Manages patient's transitions of care in collaboration with the individual, family, caregivers and interdisciplinary team members including:

- Analyzing the readiness of the patient and family to transition

- Determining appropriate level and/or setting of care

- Coordinating implementation of transition

- Assists healthcare team members to integrate the needs, preferences and strengths of the patient into the healthcare plan in order to optimize health outcomes

- Integrates information technology into systems of care to enhance safety and monitor health outcomes

- Provides leadership to address threats to healthcare safety and quality in the adult-older adult population

- Participates in development, implementation and evaluation of clinical practice guidelines that address patient needs across the adult age spectrum

- Facilitates access to and use of information and care technology based on assessment of the ability and preferences of patients across the adult age spectrum

\section{CLINICAL INQUIRY}

\section{Core CNS Competencies}

- Employs evidence-based clinical practice guidelines to guide screening and diagnosis

- Analyzes data from consultations to implement practice improvements

- Uses effective strategies for changing clinician and team behavior to encourage adoption of evidencebased practices and innovations in care delivery

- Mentors health professionals in applying the principles of evidence-based care 


\section{Validated Competencies}

- Analyzes research findings and other evidence for their potential application to clinical practice

- Integrates evidence into the health, illness and wellness management of patients, families, communities and groups

- Applies principles of evidence-based practice and quality improvement to all patient care

- Designs programs for effective implementation of research findings and other evidence in clinical practice

- Cultivates a climate of clinical inquiry across spheres of impact by evaluating the need for improvement or redesign of care delivery processes to improve safety, efficiency, reliability and quality, and disseminates expert knowledge

- Fosters an interdisciplinary approach to quality improvement, evidence-based practice, research and translation of research into practice

- Participates in establishing quality improvement agenda for unit, department, program, system or population

- Provides leadership in planning data collection and quality monitoring

- Uses quality monitoring data to assess the quality and effectiveness of clinical programs in meeting outcomes

- Develops quality improvement initiatives based on assessments

- Provides leadership in the design, implementation and evaluation of process improvement initiatives
- Provides leadership in the system-wide implementation of quality improvements and innovations

- Participates in conduct and implementation of research which includes one or more of the following:

- Identification of questions for clinical inquiry

- Conduct literature reviews, study design and implementation

- Data collection

- Dissemination of findings

\section{Adult-Gerontology CNS Competencies}

- Facilitates the incorporation of evidence based practices, products and technology that are specific to adult-older adult populations, into clinical practice and policies

- Provides leadership in identifying gaps in data and analyses specific to age-related outcomes of care

- Facilitates the incorporation of evidence related to adults-older adults when formulating and reviewing age-specific policies, procedures and protocols

- Evaluates innovative approaches to delivering care to the adult-older adult populations

- Identifies areas of inquiry relevant to the adult-older adult population

- Advocates the use of data collection tools and consents that are understandable and appropriate for adult-older adult populations 


\section{ACCNS-AG Sample Questions}

The purpose of the sample questions is to familiarize candidates with the style and format of the certification exam items.

1. TA patient with alcoholism is admitted for the third time with a diagnosis of bleeding esophageal varices. The CNS overhears a nurse on the unit state, "I don't know why we have to continue to care for someone who won't make any attempt to help himself. He knew that drinking would cause him to rebleed." The CNS's MOST APPROPRIATE response is to
A. support the nurse's response and attempt to change the patient assignment.
B. discuss with the nurse how to resolve conflict between personal and professional values.
C. report the incident to the nurse manager and suggest the nurse be counseled.
D. ignore the comment but develop an in-service on addiction issues.

2. The CNS has observed both nurses and respiratory therapists instilling saline down ET tubes prior to suctioning. The CNS can encourage researchbased practice by INITIALLY assisting the staff to
A. evaluate their current practice based on the research findings.
B. design a unit evaluation to substantiate research results in the literature.
C. incorporate research results into the unit's policy and procedure manual.
D. disseminate research findings during the next staff meeting.

3. A patient underwent an emergent percutaneous transluminal coronary angioplasty (PTCA) 3 days ago. During interdisciplinary rounds, it is reported that the patient is walking only within the room and declining to participate in progressive activity. Upon assessment, the only significant finding is a persistent bilateral dull ache over the scapulae unrelieved by oral narcotic analgesics. A priority intervention should include
A. the addition of an NSAID.
B. a modified exercise program.
C. a serial 12-lead ECG.
D. pain service referral.

4. A patient with pneumonia is being weaned after receiving mechanical ventilation for 5 days. Current ventilator settings: assist control, $\mathrm{FiO}_{2}$ $40 \%$, rate 24, tidal volume 450 and PEEP 5 . The mode is changed to CPAP with pressure support of 15. Twenty minutes later the patient is apneic. The CNS should
A. return to the previous settings but lower the rate to 20 .
B. maintain current settings but increase pressure support to 20.
C. return to the previous settings but decrease the PEEP to 2.5
D. maintain current settings but increase the $\mathrm{FiO}_{2}$ to $60 \%$.

5. The CCNS is employed at a facility considering Magnet ${ }^{\circledR}$ designation. Which of the following would be the best way for the CNS to support goal achievement?
A. become an investigator for a research study evaluating a percutaneous closure device
B. mentor medical students to demonstrate interdisciplinary, collaborative practice
C. provide leadership to a facility-wide team tasked with developing a clinical ladder program
D. establish an inpatient hospice unit to address rising length of stay rates in the ICU

6. The parents of a 17-year-old with stage IV renal cell carcinoma have been notified that further oncological treatment would be futile and the patient requested a do-not-resuscitate (DNR) status. The patient wants to go home, but the parents are anxious about their ability to provide care and are unsure they can handle watching him die at home. The CNS would MOST APPROPRIATELY recommend a
A. tour of a hospice house facility.
B. discussion with case management for long-term care placement.
C. referral to a bereavement support group.
D. consult with a hospice service equipped to provide care to this population.




\section{ACCNS-AG Sample Questions (continued)}

7. An elderly patient is admitted from a long-term care facility with altered mental status. Vital signs: BP 88/50, HR 120 - irregular and bounding, RR 28, temperature $101.9^{\circ} \mathrm{F}\left(38.8^{\circ} \mathrm{C}\right)$. The patient responds to deep pain only. The $\mathrm{CT}$ is negative. Which of the following tests will provide the BEST information to make a diagnosis?
A. 12-lead ECG, CBC and troponin levels
B. chest x-ray, ABG and Gram stain of sputum
C. urinalysis with cultures of urine, sputum and blood
D. echocardiogram, basic metabolic panel and CPK-MB

8. A new CNS graduate is promoted within the unit to a CNS role, which is the first of its kind for the hospital. When developing a strategic plan for the program, the CNS should first
A. discuss patient satisfaction data with the quality improvement coordinator.
B. identify key outcome measures with the chief nursing officer.
C. perform a review of the literature identifying barriers of APRN role integration.
D. develop a collaborative partnership with the medical director for the unit.

9. The CNS is leading a QI initiative to improve patient outcomes. The team developed a practice revision. Despite successful adoption by the majority of staff and improving metrics, the CNS observes a few team members refusing to comply with the new process. Which of the following is most beneficial for improving patient outcomes?
A. discuss performance concerns with the unit manager
B. seek an alternative solution that all staff with agree to follow
C. ensure the lack of compliance is noted when submitting the QI data
D. ask the charge nurse to consider the issue when making assignments

10. A young child has been in the unit for 3 weeks after a severe trauma in which the mother was killed and the father sustained minor injuries. The father visits daily, but the staff expresses reluctance to being assigned to the patient because the father is verbally abusive and challenges every care decision made by the team. Which of the following is the best option for the patient and family at this time?
A. tell the father he may not visit until he agrees to cooperate with team decisions
B. recognize the father is working through normal stages of grief and give him some latitude during this phase
C. request a consult by the hospital chaplain to minister to the father
D. understand the father is suffering from post- traumatic stress disorder and provide counseling 
American Association of Critical-Care Nurses. 2016. AACN Standards for Establishing and Sustaining Healthy Work Environments: A Journey to Excellence. Available at: https://www.aacn.org/nursing-excellence/standards/ aacn-standards-for-establishing-and-sustaining-healthywork-environments.

American Heart Association. 2015 Guidelines Update for Cardiopulmonary Resuscitation and Emergency Cardiovascular Care. Available at:

http://circ.ahajournals.org/content/132/18_suppl_2.toc.

Baird MS. Manual of Critical Care Nursing: Nursing Interventions and Collaborative Management. 7th ed. St. Louis, MO: Mosby; 2016.

Ball JW, Dains JE, Flynn JA, Solomon BS, Stewart RW. Seidel's Guide to Physical Examination. 8th ed. St. Louis, MO: Mosby; 2015.

Bhat P, Dretler A, Gdowski M, Ramgopal R, Williams D. The Washington Manual of Medical Therapeutics. 35th ed. Philadelphia, PA: Lippincott Williams \& Wilkins; 2016.

Bojar RM. Manual of Perioperative Care in Adult Cardiac Surgery. 5th ed. West Sussex, UK: Wiley-Blackwell; 2011.

Burns SM. AACN Essentials of Critical Care Nursing. 3rd ed. New York, NY: McGraw-Hill; 2014.

Burns SM. AACN Essentials of Progressive Care Nursing. 3rd ed. New York, NY: McGraw-Hill; 2014.

Ferri FF. Ferri's Clinical Advisor 2013. Maryland Heights, MO: Mosby; 2013.

Gray JR, Grove SK, Sutherland S. Burns and Grove's: The Practice of Nursing Research: Appraisal, Synthesis, and Generation of Evidence. 8th ed. St. Louis, MO:

Saunders/Elsevier; 2017.

Hardin SR, Kaplow R. Cardiac Surgery Essentials of Critical Care Nursing. 2nd ed. Sudbury, MA: Jones \& Bartlett; 2016.

Hardin SR. Kaplow R. Synergy for Clinical Excellence: The AACN Synergy Model for Patient Care. 2nd ed. Boston, MA: Jones \& Bartlett; 2017.

Hickey JV. The Clinical Practice of Neurological and Neurosurgical Nursing. 7th ed. Philadelphia, PA: Lippincott Williams \& Wilkins; 2013.
Irwin RS, Lilly CM, Rippe JM. Irwin \& Rippe's Manual of Intensive Care Medicine. 6th ed. Philadelphia, PA: Lippincott Williams \& Wilkins; 2014.

Irwin RS, Rippe JM, Lisbon A, Heard SO. Procedures, Techniques and Minimally Invasive Monitoring in Intensive Care. 5th ed. Philadelphia, PA: Lippincott Williams \& Wilkins; 2012.

Jacobson C, Marzlin K, Webner C. Cardiovascular Nursing Practice: A Comprehensive Resource Manual and Study Guide for Clinical Nurses. 2nd ed. Burien, WA: Cardiovascular Nursing Education Associates; 2015.

Joel LA. Advanced Practice Nursing: Essentials for Role Development. 3rd ed. Philadelphia, PA: F. A. Davis; 2013.

Kasper DL, Fauci AS. Harrison's Infectious Diseases. New York, NY: McGraw-Hill; 2017.

Kizior RJ, Hodgson BB. Saunders Nursing Drug Handbook 2017. St. Louis, MO: Saunders/Elsevier; 2017.

Kleinpell RM. Outcome Assessment in Advanced Practice Nursing. 3rd ed. New York, NY: Springer; 2013.

Loscalzo J, Harrison TR. Harrison's Cardiovascular Medicine. New York, NY: McGraw Hill; 2010.

Marino P. The ICU Book. 4th ed. Philadelphia, PA: Lippincott Williams \& Wilkins; 2013.

Meiner S. Gerontological Nursing. 5th ed. St. Louis, MO: Mosby; 2015.

Pagana KD, Pagana TJ, Pagana TN. Mosby's Diagnostic and Laboratory Test Reference. 12th ed. St. Louis, MO: Mosby/Elsevier; 2015.

Papadakis MA, McPhee SJ, Rabow MW, eds. Current Medical Diagnosis and Treatment 2017. 56th ed. New York, NY: McGraw-Hill Education; 2017.

Pasero C, McCaffrey M. Pain Assessment and Pharmacologic Management. St. Louis, MO: Elsevier; 2011.

Purnell L. Guide to Culturally Competent Health Care. 3rd ed. Philadelphia, PA: F. A. Davis; 2014. 


\section{ACCNS-AG Exam Bibliography (continued)}

Urden L, Stacy KM, Lough ME. Critical Care Nursing: Diagnosis and Management. 7th ed. St. Louis, MO: Mosby/Elsevier; 2014.

VanMeter KC, Hubert RJ. Gould's Pathophysiology for the Health Professions. 5th ed. St. Louis, MO: Saunders; 2014.

Wesley K. Huszar's Basic Dysrhythmias and Acute Coronary Syndromes - Interpretation and Management. 4th ed. St. Louis, MO: Mosby; 2011.

Whetstone-Foster J, Prevost SS. Advanced Practice Nursing of Adults in Acute Care. Philadelphia, PA:

F. A. Davis; 2012.
Wiegand DL, ed. AACN Procedure Manual for High Acuity, Progressive, and Critical Care. 7th ed. St. Louis, MO: Saunders/Elsevier; 2017.

Woo TM, Robinson MV. Pharmacotherapeutics for Advanced Practice Nurse Prescribers. 4th ed. Philadelphia, PA: F. A. Davis; 2016.

\section{Many references are available through AACN; visit www.aacn.org/store.}

More current versions may be available. 


\section{AACN Products for ACCNS-AG Exam Preparation}

AACN Certification Corporation does not approve, endorse, or require for eligibility use of any specific exam preparation products.

\begin{tabular}{|c|c|}
\hline Product Title/Description & Item \# \\
\hline *Online ACCNS-AG Certification Review Course: Individual Purchase. 2017. AACN. & ACCNSAGOD \\
\hline $\begin{array}{l}\text { * Practice ACCNS-AG Exam Questions. 2017. AACN Certification Corporation. } 70 \text { items with } \\
\text { answer rationales. }\end{array}$ & $\underline{200805}$ \\
\hline AACN Essentials of Critical Care Nursing. 4th ed. 2018. Burns SM, Delgado SA. 640 pages. & $\underline{128750}$ \\
\hline AACN Essentials of Progressive Care Nursing. 4th ed. 2018. Burns SM. Delgado SA. 576 pages. & $\underline{128765}$ \\
\hline $\begin{array}{l}\text { AACN Procedure Manual for High Acuity, Progressive, and Critical Care. 7th ed. } 2017 . \\
\text { Wiegand DL, ed. } 1312 \text { pages. }\end{array}$ & $\underline{128150}$ \\
\hline $\begin{array}{l}\text { Manual of Critical Care Nursing: Nursing Interventions and Collaborative Management. } 7 \text { th ed. } \\
\text { 2016. Baird MS. } 1008 \text { pages. }\end{array}$ & $\underline{128225}$ \\
\hline $\begin{array}{l}\text { Synergy for Clinical Excellence: The AACN Synergy Model for Patient Care. 2nd ed. 2017. Hardin S, } \\
\text { Kaplow R. } 324 \text { pages. }\end{array}$ & 100149 \\
\hline
\end{tabular}

*Included at no charge with purchase of ACCNS-AG exam.

For more details and to place an order, visit our website at www.aacn.org > Store, or call AACN Customer Care at 800-899-2226, Monday through Friday between 7:30 a.m. and 4:30 p.m. Pacific Time. 


\section{AACN Synergy Model for Patient Care}

The ACCNS-AG certification program is organized using the AACN Synergy Model for Patient Care as a framework. All competencies are from nationally recognized organizations such as the National Association of Clinical Nurse Specialist and the American Association of Colleges of Nursing.

The basic tenet of the Synergy Model is that optimal patient outcomes can be produced through the synergistic interaction between the needs of the patient and the competencies of the nurse. AACN Certification Corporation is committed to ensuring that certified nursing practice is based on the needs of patients. Integration of the AACN Synergy Model for Patient Care into AACN Certification Corporation's certification programs puts emphasis on the patient and says to the world that patients come first.

The Synergy Model creates a comprehensive look at the patient. It puts the patient in the center of nursing practice. The model identifies nursing's unique contributions to patient care and uses language to describe the professional nurse's role. It provides nursing with a venue that clearly states what we do for patients and allows us to start linking ourselves to, and defining ourselves within, the context of the patient and patient outcomes.

\section{Patient Characteristics}

The Synergy Model encourages nurses to view patients in a holistic manner rather than the "body systems" medical model. Each patient and family is unique, with a varying capacity for health and vulnerability to illness. Each patient, regardless of the clinical setting, brings a set of unique characteristics to the care situation. Depending on where they are on the healthcare continuum, patients may display varying levels of the following characteristics:

\begin{tabular}{|c|c|}
\hline Resiliency & $\begin{array}{l}\text { Capacity to return to a restorative level of functioning using compensatory/coping mechanisms; the ability to } \\
\text { bounce back quickly after an insult }\end{array}$ \\
\hline Stability & Ability to maintain a steady-state equilibrium \\
\hline Complexity & Intricate entanglement of two or more systems (e.g., body, family, therapies) \\
\hline Resource Availability & $\begin{array}{l}\text { Extent of resources (e.g., technical, fiscal, personal, psychological and social) the patient/family/community } \\
\text { bring to the situation }\end{array}$ \\
\hline Predictability & A characteristic that allows one to expect a certain course of events or course of illness \\
\hline
\end{tabular}

FOR EXAMPLE:

A healthy, uninsured, 40-year-old woman undergoing a pre-employment physical could be described as an individual who is (a) stable (b) not complex (c) very predictable (d) resilient (e) not vulnerable (f) able to participate in decision making and care, but (g) has inadequate resource availability.

On the other hand: a critically ill, insured infant with multisystem organ failure can be described as an individual who is (a) unstable (b) highly complex (c) unpredictable (d) highly resilient (e) vulnerable (f) unable to become involved in decision making and care, but (g) has adequate resource availability. 


\section{AACN Synergy Model for Patient Care (continued)}

\section{Nurse Characteristics}

Nursing care reflects an integration of knowledge, skills, abilities and experience necessary to meet the needs of patients and families. Thus, nurse characteristics are derived from patient needs and include:

Clinical Judgment

Advocacy/
Moral Agency

( AP

Caring Practices

Systems Thinking

Facilitation of

Learning

Clinical Inquiry

Clinical reasoning, which includes clinical decision making, critical thinking and a global grasp of the situation, coupled with APRN skills acquired through a process of integrating formal and informal experiential knowledge and evidence-based guidelines. Includes differential diagnosis.

Working on another's behalf and representing the concerns of the patient/family and nursing staff; serving as a moral agent in identifying and helping to resolve ethical and clinical concerns within and outside the clinical setting.

APRN activities that create a compassionate, supportive and therapeutic environment for patients and staff, with the aim of promoting comfort and healing and preventing unnecessary suffering. Includes but is not limited to vigilance, engagement and responsiveness of caregivers, including family and healthcare personnel. Content in this category includes pain management, infection control, risk assessment and the clinical nurse specialist/patient relationship

Working with others (e.g., patients, families, healthcare providers) in a way that promotes/encourages each person's contributions toward achieving optimal/realistic patient/family goals. Includes initiating referrals, providing consultation and the coordination of inter- and intradisciplinary teams to develop or revise plans of care focused on the concerns of the patient, family or both

Body of knowledge and tools that allow the APRN to manage whatever environmental and system resources exist for the patient/family and staff, within or across healthcare and non-healthcare systems. Includes analysis and promotion of cost-effective resource utilization that results in optimal patient outcomes.

The sensitivity to recognize, appreciate and incorporate differences into the provision of care. Differences may include, but are not limited to, cultural differences, spiritual beliefs, gender, race, ethnicity, lifestyle, socioeconomic status, age and values.

The ability to facilitate learning for patients/families, nursing staff, other members of the healthcare team and community. Includes both formal and informal facilitation of learning.

The ongoing process of questioning and evaluating practice and providing informed practice. Creating changes through evidence-based practice, research utilization and experiential knowledge.

Nurses become competent within each continuum at a level that best meets the fluctuating needs of their population of patients. More compromised patients have more severe or complex needs, requiring nurses to have advanced knowledge and skills in an associated continuum.

\section{FOR EXAMPLE:}

If the patient was stable but unpredictable, minimally resilient and vulnerable, primary competencies of the nurse would be centered on clinical judgment and caring practices (which includes vigilance). If the patient was vulnerable, unable to participate in decision making and care, and had inadequate resource availability, the primary competencies of the nurse would focus on advocacy and moral agency, collaboration and systems thinking.

Although all eight competencies are essential for contemporary nursing practice, each assumes more or less importance depending on a patient's characteristics. Synergy results when a patient's needs and characteristics are matched with the nurse's competencies.

The certification program is also based on the three spheres of impact in which CNSs operate: Patient, Nurses/Nursing Practice and Organizations/Systems. A sphere of impact identifies the focus of practice activities and target outcomes associated with the area. The certification exam is based on the activities performed by CNSs in connection with the eight nurse characteristics in the context of the three spheres of impact.

Based on the most recent AACN Certification Corporation study of nursing practice, the test plans for our certification exams reflect the Synergy Model as well as findings related to nursing care of the patient population studied (e.g., CNS practice in the care of adult-gerontology patients, covering the spectrum of wellness through acute care).

For more information about the AACN Synergy Model for Patient Care visit www.aacn.org. 


\section{Educational Eligibility Form \\ ACCNS-AG Certification for Adult-Gerontology Clinical Nurse Specialists \\ To be completed by Program Director and returned to AACN Certification Corporation.}

CANDIDATE NAME

\begin{tabular}{lllll}
\hline CANDIDATE EMAIL & Last & First & MI & \\
\hline
\end{tabular}

\section{ADULT-GERONTOLOGY CLINICAL NURSE SPECIALIST PROGRAM INFORMATION}

SCHOOL NAME

\section{SCHOOL ADDRESS}

PROGRAM TYPE $\square$ Adult-Gerontology CNS $\square$ Other(specify):

DEGREE AWARDED $\square$ Master's $\square$ DNP $\square$ Post-Graduate Certificate

PROGRAM START DATE

$$
(\mathrm{MM} / \mathrm{DD} / \mathrm{YY})
$$

GRADUATION DATE

$(\mathrm{MM} / \mathrm{DD} / \mathrm{YY})$

PROGRAM DESCRIPTION - for time period applicant was in program

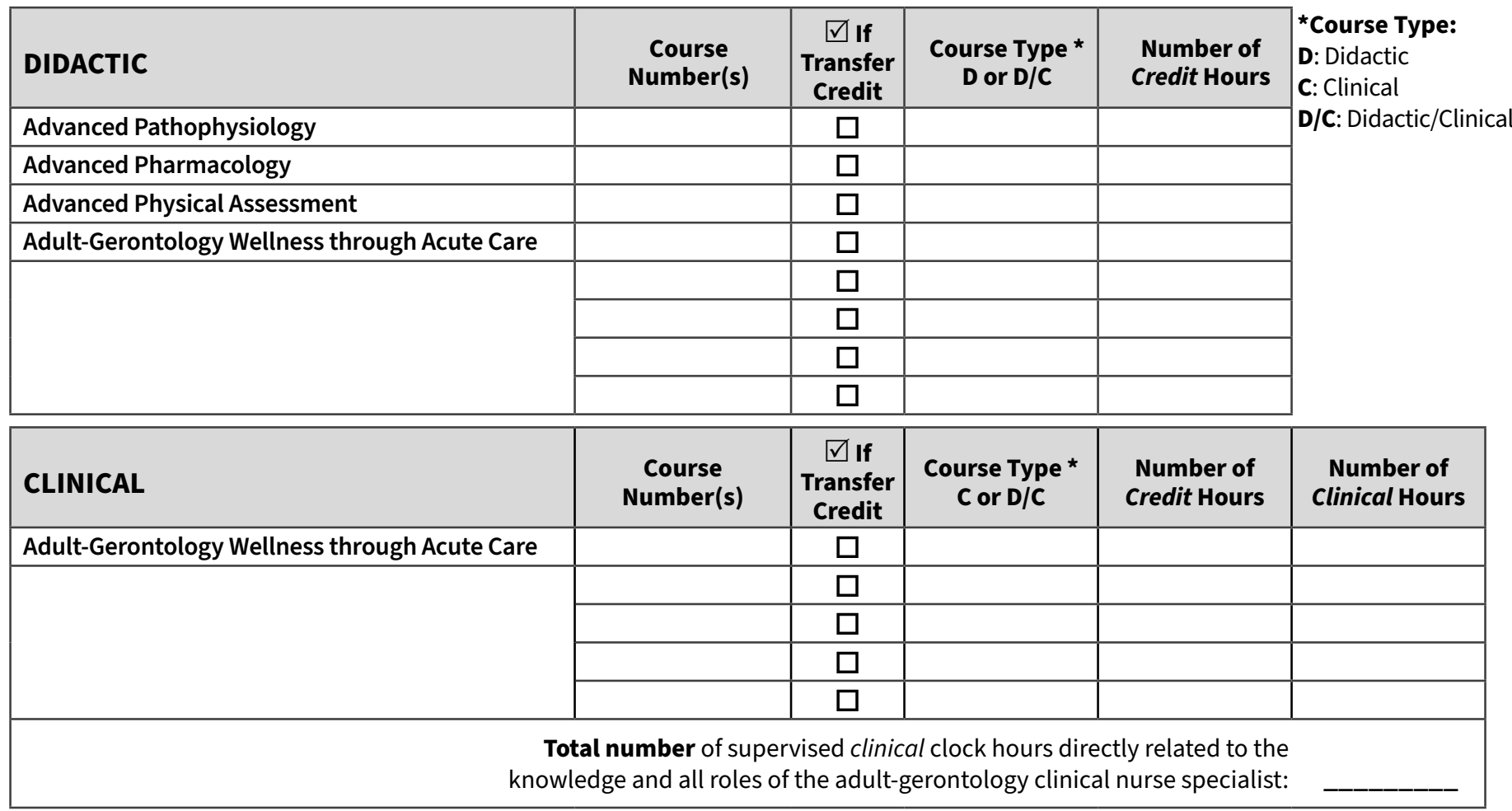

The following statements apply to the advanced practice education program completed by the candidate (check all that apply):

$\square$ A portion of the total clinical hours within the program focused on wellness in the adult-gerontology patient population.

$\square$ A portion of the total clinical hours within the program focused on acute care in the adult-gerontology patient population.

My signature on this form attests to the fact that at the time of graduation the above-named applicant met the program requirements noted and checked above. I understand that AACN Certification Corporation may contact me, if needed, for clarification of this candidate's eligibility.

Program Director Signature

Phone

Date

Printed Name

Email

This completed form with an original signature may be submitted to AACN Certification Corporation via mail to:

AACN Certification Corporation, 27071 Aliso Creek Road, Aliso Viejo, CA 92656.

Alternatively, the form may be scanned/emailed directly from the school to APRNcert@aacn.org. 


\section{ACCNS-AG Exam Application}

1. REGISTRATION INFORMATION

AACN CUSTOMER:

LEGAL NAME:

RN/APRN LICENSE:

PLEASE PRINT CLEARLY. PROCESSING WILL BE DELAYED IF INCOMPLETE OR NOT LEGIBLE. LEGAL NAME AS IT APPEARS ON YOUR GOVERNMENT-ISSUED ID CARD IS REQUIRED FOR EXAM.

Exp. Date Number $\quad$ State Exp. Date

Last

First

MI

Maiden

HOME ADDRESS:

EMAIL:

City

State

Zip

HOME PHONE:

EMPLOYER NAME:

BUSINESS PHONE:

\section{EMPLOYER ADDRESS:}

2. AACN MEMBERSHIP

I would also like to join/renew/extend my AACN membership at this time and select member pricing for my exam fees:

(check one box only)

$\square$ 1-year AACN membership................................................\$ 78

$\square$ 2-year AACN membership....................................................\$148

$\square$ 3-year AACN membership..................................................\$200

AACN membership includes nonrefundable $\$ 12$ and $\$ 15$ one-year subscriptions to Critical Care Nurse ${ }^{\circledR}$ and the American Journal of Critical Care ${ }^{\circledR}$, respectively. AACN dues are not deductible as charitable contributions for tax purposes, but may be deducted as a business expense in keeping with Internal Revenue Service regulations.

Member exam fee (\$260) + 1-year Membership (\$78) = Savings of $\$ 32$ over Nonmember fee

3. EXAM FEES

\begin{tabular}{|c|c|c|c|c|}
\hline \multirow{2}{*}{ ACCNS-AG } & \multicolumn{2}{|c|}{ Initial Exam Fee } & \multicolumn{2}{c|}{ Retest Fee } \\
\cline { 2 - 5 } & AACN Member & Nonmember & AACN Member & Nonmember \\
\hline Check one box only & $\square \$ 265$ & $\square \$ 375$ & $\square \$ 205$ & $\square \$ 310$ \\
\hline
\end{tabular}

Check this box if you've attached a request and supporting documentation for special testing accommodations.

Membership Fee

$\$$

$+$

Exam Fee:

\$

$=$

Total Payment:

$\$$

4. PAYMENT INFORMATION - application must be accompanied by payment

$\square$ Check or money order attached - payable to AACN Certification Corporation. U.S. funds only.

Bill my credit card: $\square$ Visa $\square$ MasterCard $\square$ American Express $\square$ Discover Card
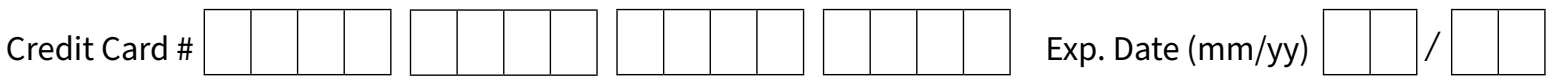

Name on Card

Signature

Amount Billed \$ Address of Payor (if different than applicant)

$\square$ Please do not include my name on lists sold to other organizations. 


\section{ACCNS-AG Exam Application}

\section{DEMOGRAPHIC INFORMATION}

Check one box in each category. Information used for statistical purposes and may be used in eligibility determination.

$\begin{array}{ll}\text { Primary Area Employed } & \square \text { Subacute Care (28) } \\ \square \text { Acute Hemodialysis Unit (21) } & \square \text { Surgical ICU (07) } \\ \square \text { Burn Unit (13) } & \square \text { TeleICU (37) } \\ \square \text { Cardiac Rehabilitation (26) } & \square \text { Telemetry (20) } \\ \square \text { Cardiac Surgery/OR (36) } & \square \text { Trauma Unit (11) } \\ \square \text { Cardiovascular/Surgical ICU (09) } & \square \text { Other - specify below } \\ \square \text { Catheterization Lab (22) } & \\ \square \text { Combined Adult/Ped. ICU (23) } & \\ \square \text { Combined ICU/CCU (01) } & \text { Primary Position Held } \\ \square \text { Coronary Care Unit (03) } & \square \text { Academic Faculty (07) } \\ \square \text { Corporate Industry (24) } & \square \text { Acute Care Nurse Practitioner (09) } \\ \square \text { Crit. Care Transport/Flight (17) } & \square \text { Bedside/Staff Nurse (01) } \\ \square \text { Direct Observation Unit (39) } & \square \text { Case Manager (39) } \\ \square \text { Emergency Dept. (12) } & \square \text { Charge Nurse (45) } \\ \square \text { General Med./Surg. Floor (18) } & \square \text { Clinic Nurse (40) } \\ \square \text { Home Care (25) } & \square \text { Clinical Coordinator (44) } \\ \square \text { Intensive Care Unit (02) } & \square \text { Clinical Director (04) } \\ \square \text { Interventional Cardiology (31) } & \square \text { Clinical Nurse Specialist (08) } \\ \square \text { Long-Term Acute Care (27) } & \square \text { Corporate/Industry (11) } \\ \square \text { Medical Cardiology (34) } & \square \text { Hospital Administrator (38) } \\ \square \text { Medical ICU (04) } & \square \text { Internist (37) } \\ \square \text { Medical Surgical ICU (35) } & \square \text { Legal Nurse Consultant (47) } \\ \square \text { Neonatal ICU (06) } & \square \text { Manager (03) } \\ \square \text { Neuro./Neurosurgical ICU (10) } & \square \text { Nurse Anesthetist (02) } \\ \square \text { Oncology Unit (19) } & \square \text { Nurse Educator (46) } \\ \square \text { Operating Room (15) } & \square \text { Nurse Midwife (13) } \\ \square \text { Outpatient Clinic (29) } & \square \text { Nurse Practitioner (05) } \\ \square \text { Pediatric ICU (05) } & \square \text { Outcomes Manager (42) } \\ \square \text { Private Practice (32) } & \square \text { Physician (16) } \\ \square \text { Progressive Care Unit (16) } & \square \text { Physician Assistant (17) } \\ \square \text { Recovery Room/PACU (14) } & \square \text { Researcher (18) } \\ \square \text { Respiratory ICU (08) } & \square \text { Respiratory Therapist (19) } \\ \square \text { Stepdown Unit (30) } & \end{array}$

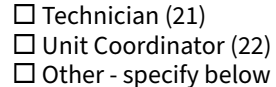

$\square$ Unit Coordinator (22)

-

Highest Nursing Degree
$\square$ Associate's Degree

$\square$ Bachelor's Degree

$\square$ Diploma

$\square$ Doctorate

$\square$ Master's Degree

\section{Ethnicity}

$\square$ African American (02)

$\square$ Asian (05)

$\square$ Hispanic (03)

$\square$ Native American (04)

$\square$ Pacific Islander (06)

$\square$ White/Non-Hispanic (01)

$\square$ Other - specify below

Primary Type of Facility in Which

Employed

$\square$ College/University (08)

$\square$ Community Hospital (Nonprofit) (01) Date of Birth: (mm/dd/yy):

$\square$ Community Hospital (Profit) (02)

$\square$ Corporate/Industry (11)

$\square$ County Hospital (07)

$\square$ Federal Hospital (05)

$\square$ HMO/Managed Care (12) $\square$ Home Health (13)

$\square$ Long-Term Acute Care Hosp. (16)

$\square$ Military/Government Hospital (04)

99)

$\square$ Non-Academic Teaching Hosp. (14)

Registry (10)

$\square$ Self-Employed (09)

$\square$ State Hospital (06)

$\square$ Travel Nurse (15)

$\square$ University Med. Ctr. (03)

$\square$ Other - specify below

Number of Beds in Institution:

Years of Experience in Nursing:

(99)

Years of Experience in Acute/Critica Care Nursing:

Gender:

$\square$ Male $\square$ Female $\square$ Non-binary

\section{HONOR STATEMENT}

Complete the ACCNS-AG Honor Statement on page 29 and submit with application.

\section{ADDITIONAL REQUIRED DOCUMENTATION}

- Official, final transcripts for all graduate-level nursing coursework showing degree/date conferred

- Secure, electronic transcripts may be emailed directly from the school to APRNcert@aacn.org.

- Mailed transcripts must be sent to AACN in a sealed envelope directly from the school.

- Educational Eligibility Form completed/signed by your program director

AACN will reach out to your program director to request completion of the form via AACN's online Portal, OR a printed form (see page 26) with original signature may be submitted with your application. Your school may email the form directly to APRNcert@aacn.org.

8. SUBMIT WITH PAYMENT TO AACN Certification Corporation, 27071 Aliso Creek Road, Aliso Viejo, CA 92656-3399

Retest applications may be faxed to 949-362-2020.

NOTE: Allow 1 to 4 weeks from the date received by AACN Certification Corporation for application processing. If your school must be contacted to verify eligibility or application is incomplete, processing may be delayed.

Questions? Please visit www.aacn.org/certification, email APRNcert@aacn.org or call us at 800-899-2226. 


\section{ACCNS-AG Exam Honor Statement}

PROCESSING WILL BE DELAYED IF INCOMPLETE OR NOT LEGIBLE.

NAME:

AACN CUSTOMER \#:

Last

First

$\mathrm{Ml}$

I hereby apply for the ACCNS-AG certification exam. I have read and understand the exam policies and eligibility requirements as documented in the ACCNS-AG Exam Handbook and the Certification Exam Policy Handbook.

EDUCATION: I acknowledge that certification depends upon successful completion of the specified requirements. I authorize AACN Certification Corporation to contact my graduate nursing program to verify my educational eligibility for the ACCNS-AG certification exam.

LICENSURE: I possess a current, unencumbered U.S. RN or APRN license. My (state) nursing license (number) is due to expire (date). An unencumbered license is not currently being subjected to formal discipline by the board of nursing in the state(s) in which I am practicing and has no provisions or conditions that limit my nursing practice in any way. I understand that I must notify AACN Certification Corporation within $\mathbf{3 0}$ days if any provisions or conditions are placed against my RN or APRN license(s) in the future. I understand I may be eligible for Conditional Certification if my license becomes encumbered.

AUDIT: I understand that my certification eligibility is subject to audit, and failure to respond to or pass an audit will result in revocation of certification.

ETHICS: I understand the importance of ethical standards and agree to act in a manner congruent with the ANA Code of Ethics for Nurses.

SCORE REPORTING: I authorize AACN Certification Corporation to release my ACCNS-AG exam pass/fail status to the State Board(s) of Nursing to which I have applied or intend to apply for advanced practice licensure. I understand that my ACCNS-AG exam pass/fail status and a breakdown of my exam scores by content area will be reported to the program director of my school.

NONDISCLOSURE OF EXAM CONTENT: Submission of this application indicates my agreement to keep the contents of the exam confidential and not disclose or discuss specific exam content with anyone except AACN Certification Corporation. Per AACN Certification Corporation policy, sharing of exam content is cause for revocation of certification.

To the best of my knowledge, the information contained in this application is accurate and submitted in good faith. My signature below indicates I have read this honor statement and meet the eligibility requirements as outlined.

Please allow 1 to 4 weeks from the date received by AACN Certification Corporation for processing of your application. 


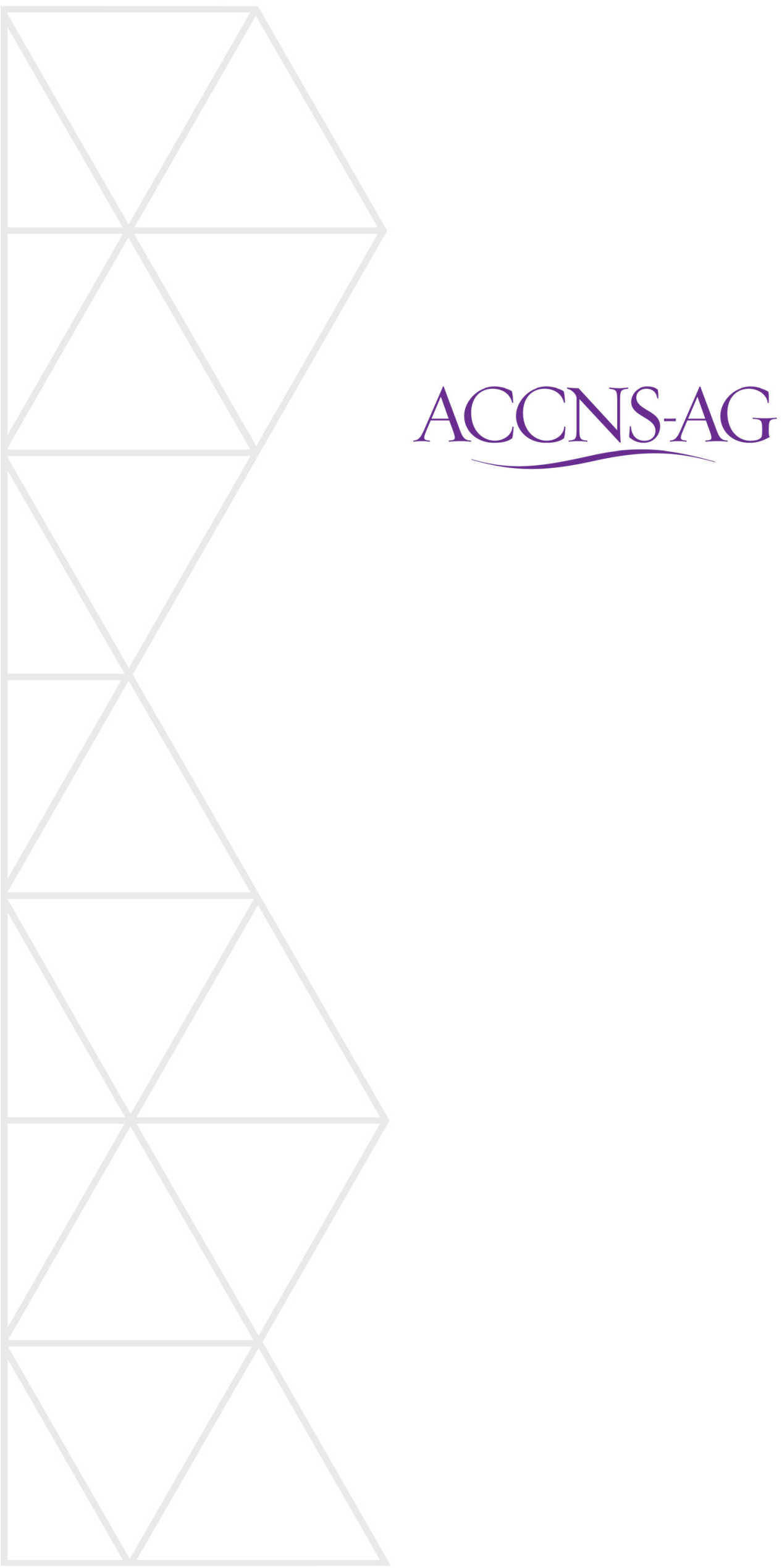

